\title{
Clinical outcomes and fate of the distal aorta following 1-stage repair of extensive chronic thoracic aortic dissection
}

\author{
Nicholas T. Kouchoukos, MD, ${ }^{\mathrm{a}}$ Alexander Kulik, MD, MPH, ${ }^{\mathrm{b}}$ and Catherine F. Castner, BSN, $\mathrm{RN}^{\mathrm{a}}$
}

\begin{abstract}
Objective: To analyze clinical outcomes and distal segmental aortic growth and aortic reoperation rates following 1-stage open repair of extensive chronic aortic dissection that included resection and graft replacement of the aneurysmal descending thoracic aorta.
\end{abstract}

\begin{abstract}
Methods: Among 68 patients undergoing extensive 1-stage repair of chronic aortic dissection that included the ascending aorta, arch, and varying lengths of the descending thoracic aorta, 66 were hospital survivors (early mortality $2.9 \%)$. Fifty-one of these patients $(77 \%)$ had serial imaging studies suitable for calculation of growth rates of the remaining thoracic and upper abdominal aorta. The mean duration of follow-up was 5.8 years and extended to 13.7 years.

Results: The overall growth rate of the distal aorta for the entire cohort was $0.10 \mathrm{~mm} / \mathrm{year}$. For 28 patients followed for $>5$ years, the growth rate was $0.03 \mathrm{~mm} /$ year. Three patients required reoperation on the contiguous thoracic or abdominal aorta for aneurysmal degeneration 8 months, 34 months, and 6.2 years postoperatively. Actuarial freedom from reoperation for aneurysmal growth of the distal aorta at 5 and 10 years was $96.3 \%$ and $93.3 \%$, respectively. Actuarial freedom from any aortic reoperation at 5 years and 10 years was $88.6 \%$ and $82.7 \%$, respectively. Actuarial survival at 5,7 , and 10 years was $78.2 \%, 71.2 \%$, and $57.3 \%$, respectively.

Conclusions: Our extended experience with the 1-stage procedure confirms its safety and feasibility for treatment of extensive chronic thoracic aortic dissection. It is associated with a low incidence of reoperation on the contiguous aorta for aneurysmal degeneration. It represents a viable alternative to 2-stage and hybrid procedures that are also used to treat this condition. (J Thorac Cardiovasc Surg 2013;146:1086-91)
\end{abstract}

Progressive dilation of the thoracic aorta after successful repair of acute type A aortic dissection is not uncommon, and up to $30 \%$ of patients require operative intervention on the remaining dissected thoracic aorta in the 5 to 10 years following initial repair. ${ }^{1-4}$ Unrecognized aortic dissection can occur spontaneously or after operations on the coronary arteries or cardiac valves, resulting in aneurysmal dilatation of the dissected thoracic aorta that requires surgical treatment. ${ }^{5,6}$ Retrograde dissection and enlargement of the aortic arch and ascending aorta can also occur in patients who sustain type B aortic dissection.

The optimal method of surgical management of patients who develop substantial enlargement of the remaining ascending aorta, aortic arch and descending thoracic aorta (DTA) after acute dissection has not been clearly established. Options for management include staged procedures, commonly using the elephant trunk technique, hybrid

From the Division of Cardiovascular and Thoracic Surgery, ${ }^{\mathrm{a}}$ Missouri Baptist Medical Center, St Louis, Mo; and the Lynn Heart and Vascular Institute, ${ }^{\text {b }}$ Boca Raton Regional Hospital, Boca Raton, Fla.

Disclosures: Authors have nothing to disclose with regard to commercial support.

Read at the 39th Annual Meeting of The Western Thoracic Surgical Association, Coeur d'Alene, Idaho, June 26-29, 2013.

Received for publication June 19, 2013; accepted for publication July 11, 2013; available ahead of print Sept 3, 2013.

Address for reprints: Nicholas T. Kouchoukos, MD, Missouri Baptist Medical Center, 3001 N Ballas Rd, Suite 360 C, St Louis, MO 63131 (E-mail: ntkouch@aol.com). $0022-5223 / \$ 36.00$

Copyright (c) 2013 by The American Association for Thoracic Surgery http://dx.doi.org/10.1016/j.jtcvs.2013.07.031 procedures using endovascular grafts to exclude the aneurysmal descending thoracic aortic segments, and 1-stage procedures.

A concern with all of these techniques is the fate of the dissected aorta distal to the site of the graft (stented or unstented) in the DTA and the need for further interventions on this aortic segment. We present here our experience with a 1-stage technique for patients with chronic extensive thoracic aortic dissection, focusing on the clinical outcomes and the distal aortic segmental growth and reoperation rates.

\section{PATIENTS AND METHODS Patient Characteristics}

During a 17-year interval ending in December 2011, 68 patients with chronic, extensive thoracic aortic dissection with aneurysmal enlargement underwent 1-stage resection and graft replacement of the ascending aorta, the aortic arch, and varying lengths of the DTA. Sixty-four patients had type A aortic dissection and four had type B dissection. This study was reviewed by the Institutional Review Board of the Missouri Baptist Medical Center and was exempt from Board Approval.

The mean patient age was 58 years (range, $22-81$ years), and $72 \%$ were men. Fifty-two patients had undergone previous repair of acute type A aortic dissection. A type A dissection developed in 10 patients during or after aortic valve replacement/repair or coronary artery bypass grafting (CABG). Four patients had type B dissection with proximal extension of the dissection into the aortic arch and ascending aorta that was initially managed with medical therapy. The remaining 2 patients had chronic type A dissections that were initially managed without operation. Eight patients $(11.8 \%$ ) had Marfan Syndrome, 1 had Loewys-Dietz syndrome, and 1 had both Loewys-Dietz syndrome and type I Ehlers-Danlos Syndrome. 


\section{Abbreviations and Acronyms \\ $\mathrm{CABG}=$ coronary artery bypass grafting \\ DTA $=$ descending thoracic aorta}

Among the 62 patients undergoing reoperation, the mean interval between the initial and the 1-stage procedure was 63 months (range, 1.7-265 months). At the time of reoperation, the dissection extended into the abdominal aorta in all but 1 patient. The indications for the 1-stage procedure and the preoperative studies performed have been previously reported. ${ }^{7}$ During the study interval, no other technique was employed for extensive aneurysmal dilation of a chronically dissected aorta involving the remaining ascending aorta, the aortic arch, and the DTA. Patients in whom the aneurysmal enlargement extended into the abdominal aorta were treated with staged procedures.

\section{Operative Technique}

Our current operative technique has been previously reported. ${ }^{7,8}$ In brief, it involves use of a bilateral anterior thoracotomy through the fourth intercostal space, transverse sternotomy, peripheral venous cannulation through the right common femoral vein using a 2-stage cannula with the tip positioned in the superior vena cava, and cannulation of the right common femoral artery and the right axillary artery. A branched aortic graft is used attaching the 3 adjacent branches end-to-end to the 3 brachiocephalic arteries. ${ }^{9}$ This was accomplished in the most recent 42 patients during a brief (mean $13 \pm 8$ minutes) interval of hypothermic circulatory arrest followed by an interval of hypothermic $\left(20^{\circ} \mathrm{C}-22^{\circ} \mathrm{C}\right)$ brain perfusion through the right axillary artery (mean $47.4 \pm 6.4$ minutes). ${ }^{9}$ Cerebral oxygen saturation was monitored during this interval using the Invos Cerebral Oximeter (Somanetics Corp, Troy, Mich).

After completion of the arch anastomoses, the site for attachment of the distal end of the aortic graft to the DTA is selected. This is generally where the diameter of the remaining dissected aorta does not exceed 3.5 to $4.0 \mathrm{~cm}$. A segment of the septum between the true and false lumens is excised to permit perfusion of both channels. Patent intercostal arteries above the seventh intercostal space are ligated. If the aorta is divided below this level, the distal aorta is beveled when feasible to preserve the intercostal arteries. After this anastomosis is completed and air is evacuated from the graft, flow to the lower body is established in the antegrade direction from the axillary artery, and rewarming is initiated.

During rewarming, aortic valve or aortic root replacement and CABG are performed, if indicated. The proximal end of the aortic graft is sutured to the ascending aorta at the level of the aortic commissures, to an existing aortic graft, or to a newly inserted composite graft. Saphenous vein bypass grafts, if present, are anastomosed to the aortic graft.

\section{Extent of Resection and Concomitant Procedures}

The remaining ascending aorta, the entire aortic arch, and varying lengths of the DTA were resected and replaced in all patients. The extent of DTA replacement and the concomitant procedures performed are shown in Table 1.

\section{Follow-up}

The mean duration of clinical follow-up of the entire cohort was 5.8 years and extended to 13.7 years. Serial computed tomography scans or magnetic resonance angiographic studies were obtained on all hospital survivors 4 to 6 months postoperatively, and at yearly intervals thereafter. Fifty-one of the 66 hospital survivors (77\%), had serial imaging studies suitable for calculation of growth rates of the remaining DTA and abdominal aorta.
TABLE 1. Extent of descending thoracic aortic replacement and concomitant procedures

\begin{tabular}{lc}
\hline \multicolumn{1}{c}{ Operative details } & No. of patients \\
\hline Extent of descending thoracic aortic replacement & \\
Proximal 1/3 & 12 \\
Proximal 1/2-3/4 & 48 \\
All & 7 \\
Concomitant procedures & \\
Aortic root replacement & 8 \\
Aortic valve replacement & 19 \\
Coronary artery bypass grafting & 6 \\
Mitral valve replacement & 1 \\
Other & 1 \\
\hline
\end{tabular}

\section{Radiographic Analysis}

The initial postoperative and final computed tomography or magnetic resonance angiographic images were used to calculate changes in aortic diameter in the remaining DTA or at the level of the aortic hiatus if all of the DTA had been replaced. The largest short-axial diameter of the outer contour of the affected aortic segment was measured. ${ }^{10}$ The growth rate was calculated as the difference in maximal diameter between the initial and final measurements divided by the time interval. Scans of the lower abdominal aorta and iliac arteries were not consistently obtained but were evaluated, when available, for growth. All imaging studies were reviewed by at least 1 radiologist and 1 surgeon (N.T.K. or A.K.) The mean duration of follow-up for the imaged patients was 5.3 years and extended to 12.8 years. Twenty-eight patients had radiographic follow-up for $>5$ years. Follow-up was current to October 2012 .

\section{Statistical Analyses}

Standard descriptive statistical analyses were used. Continuous data are presented as means \pm standard deviation. Categorical data are presented as proportions. Nonparametric estimates of freedom from all-cause death and reoperation were determined by using the Kaplan-Meier method and are reported as means. Data were analyzed in Intercooled Stata 9.2 software (StataCorp, College Station, Tex).

\section{RESULTS}

\section{Early Mortality}

The hospital and 30-day mortality rates were $2.9 \%$ (2 patients). A 71-year old woman with an expanding chronic type A dissection and severe aortic regurgitation after a CABG procedure died in the operating room of biventricular failure. A 47-year old man died on postoperative day 8 after a cardiac arrest. He had repair of an acute type A dissection 9 months previously and required reoperation for severe persisting aortic regurgitation and heart failure combined with progressive enlargement of the aortic arch and descending thoracic aorta. The 1-year mortality rate was $11.8 \%$ (8 patients).

\section{In-Hospital Morbidity}

The major postoperative complications are shown in Table 2. The intraoperative mean transfusion requirements were $8.5 \pm 4.6$ units of packed red blood cells, $7.0 \pm 3.8$ units of fresh frozen plasma, $4.9 \pm 3.0$ units of platelets, 
TABLE 2. In-hospital morbidity (67 operative survivors)

\begin{tabular}{lcc}
\hline \multicolumn{1}{c}{ Complication } & No. of patients & $\%$ \\
\hline Reoperation for bleeding & 6 & 9.0 \\
Stroke* & 1 & 1.5 \\
Spinal cord ischemic injury (paraplegia) & 1 & 1.5 \\
Temporary neurologic dysfunction & 6 & 9.0 \\
Renal failure (dialysis) & 5 & 7.5 \\
Ventilatory support $>72 \mathrm{~h}$ & 30 & 44.8 \\
Tracheostomy $\dagger$ & 10 & 14.9 \\
\hline
\end{tabular}

*No neurologic defecit (diagnosis by computed tomography). $\dagger$ Six patients were discharged with a tracheostomy.

and $5.9 \pm 10.0$ units of cryoprecipitate. The postoperative transfusion requirements for the 4 blood components were 3.2 units, 1.9 units, 0.7 units, and 1.1 units, respectively. There were no deep chest wound infections. The mean duration of the postoperative hospital stay was 20.5 days (median, 12; range, 6-71 days).

\section{Growth of Distal Aorta}

The diameters of the remaining distal thoracic or upper abdominal aorta for the 51 patients with serial imaging studies obtained early postoperatively and at the time of last follow-up are shown in Figure 1. The overall growth rate for the entire cohort was $0.10 \mathrm{~mm} /$ year. Twenty-five patients had zero or negative growth. The growth rate was $0.26 \mathrm{~mm} /$ year for the remaining 26 patients. Of 28 patients followed for $>5$ years, the aortic growth rate was $0.03 \mathrm{~mm} /$ year. Twelve of these patients had zero or negative growth rates and the growth rate for the remaining 16 patients was $0.08 \mathrm{~mm} /$ year.

\section{Reoperations}

Contiguous aorta. Three patients required reoperation on the contiguous thoracic or abdominal aorta distal to the

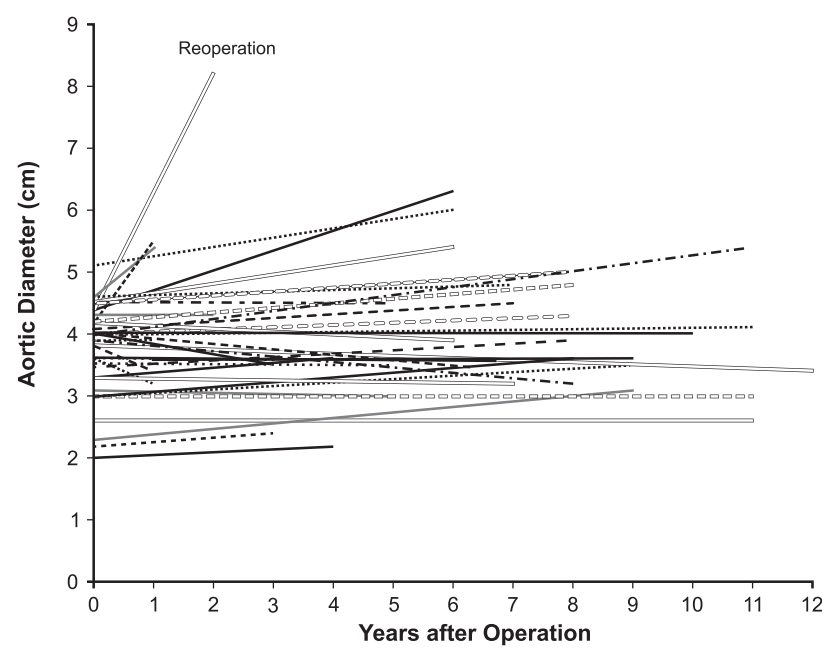

FIGURE 1. Change in diameter of the remaining distal thoracic or upper abdominal aorta at the hiatus determined by serial imaging after surgery. Each line represents 1 patient. aortic graft for aneurysmal degeneration at 8 months, 34 months, and 6.2 years after the 1 -stage procedure. The patient who required reoperation at 8 months had Loewys-Dietz and type 1 Ehlers-Danlos syndromes. She required the one-stage procedure four months after repair of an acute type A aortic dissection. Actuarial freedom from reoperation for aneurysmal growth of the contiguous distal aorta at 5 and 10 years was $96.3 \%$ and $93.3 \%$, respectively (Figure 2). No patient died following reoperation.

Other aortic operations. Six other patients required operations on the aorta or its major branches, or on the aortic graft for indications unrelated to aneurysmal growth of the contiguous aorta. Three patients required repair of a false aneurysm at the proximal or distal suture line of the aortic graft, 1 for a false aneurysm of the aortic graft due to erosion, and 2 for infrarenal abdominal and iliac artery aneurysms. All 6 patients survived reoperation. Actuarial freedom from any aortic reoperation at 5 years and 10 years was $88.6 \%$ and $82.7 \%$, respectively (Figure 3 ).

\section{Late Mortality}

During the follow-up interval, which extends to 13.7 years, 23 deaths occurred between 2 months and 12 years. The modes of death (in-hospital and late) are summarized in Table 3. No patient whose cause of death was known died of aortic rupture. Forty-eight patients have been followed for $>3$ years, 37 for $>5$ years, and 28 for $>7$ years. Actuarial survival at 5, 7, and 10 years was $78.2 \%, 71.2 \%$, and $57.3 \%$, respectively (Figure 4 ).

\section{DISCUSSION}

Our extended experience with the one- stage procedure for treatment of extensive chronic aortic dissection with aneurysmal degeneration confined to the thoracic aorta

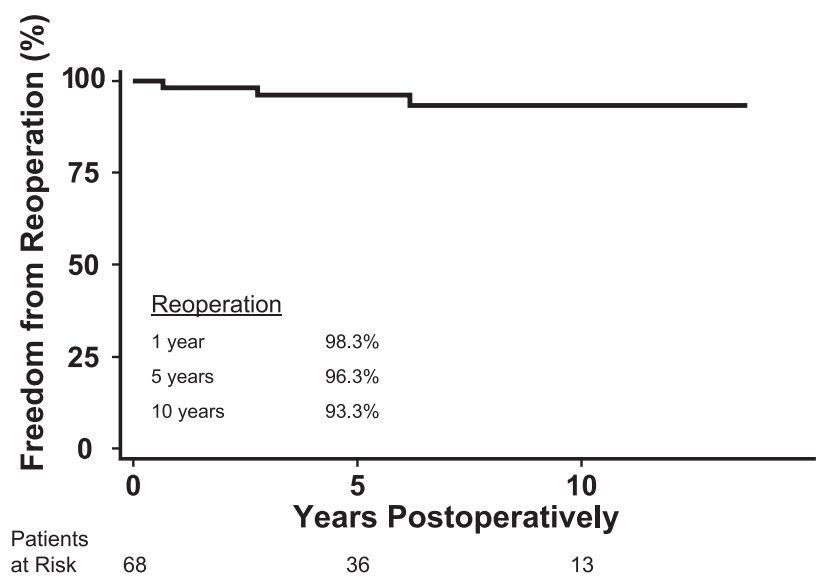

FIGURE 2. Freedom from reoperation on the contiguous aorta for aneurysmal degeneration after surgery for extensive thoracic aortic dissection. 


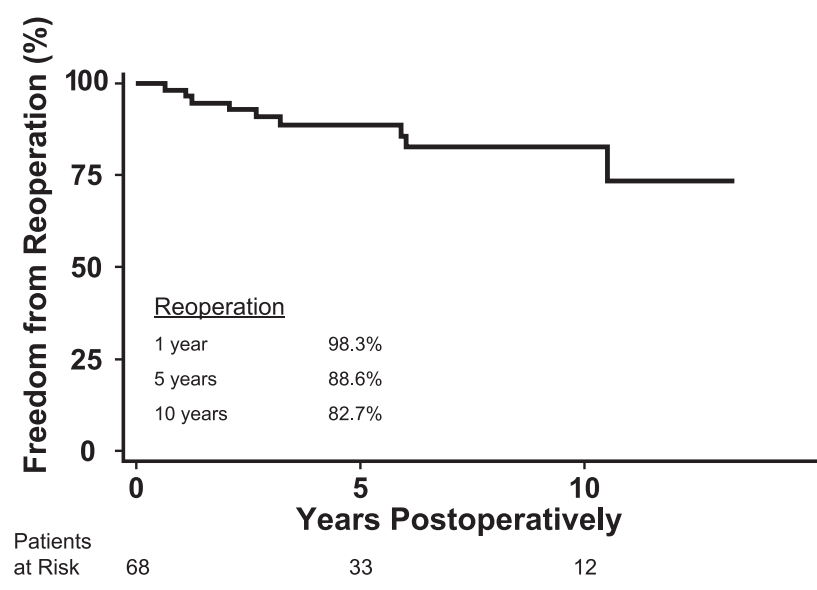

FIGURE 3. Freedom from any aortic reoperation after surgery for extensive thoracic aortic dissection.

indicates that it is a safe and suitable alternative to the 2 -stage procedure. The early mortality $(2.9 \%)$ does not exceed that reported for the first stage of the 2-stage (elephant-trunk) procedure in 5 large series. ${ }^{11-15}$ The intraoperative transfusion requirements were substantially less than those reported for the first-stage elephant trunk procedure by Safi and colleagues ${ }^{12}$ and LeMaire and colleagues. ${ }^{16}$ The prevalence of stroke, renal failure, and left recurrent laryngeal nerve injury did not exceed that reported for the first-stage in the 5 referenced series. ${ }^{11-15}$ Spinal cord ischemic injury occurred in 1 patient in our series, whereas no patient developed this complication after the first stage in the 5 large series. An important caveat for these comparisons is that the reports of the 2-stage procedures included patients with other conditions besides chronic aortic dissection, and the outcomes were not stratified for these disorders.

The relatively high prevalence of substantial pulmonary dysfunction and need for tracheostomy has been considered by other groups to be a significant limitation of the 1-stage procedure. ${ }^{16-18}$ It is important to note that the cumulative frequency of these complications has not been thoroughly documented in reports of the 2-stage procedure. The prevalence of tracheostomy was reported in only 1 of the

TABLE 3. Mode of early and late deaths

\begin{tabular}{lc}
\hline \multicolumn{1}{c}{ Cause } & No. of patients \\
\hline Sepsis & 4 \\
Cardiac failure & 4 \\
Respiratory failure & 1 \\
Sudden death & 1 \\
Renal failure & 1 \\
Multiple system organ failure & 3 \\
Intestinal infarction & 1 \\
Unknown & 7 \\
Cancer & 2 \\
Other (car accident) & 1 \\
\hline
\end{tabular}

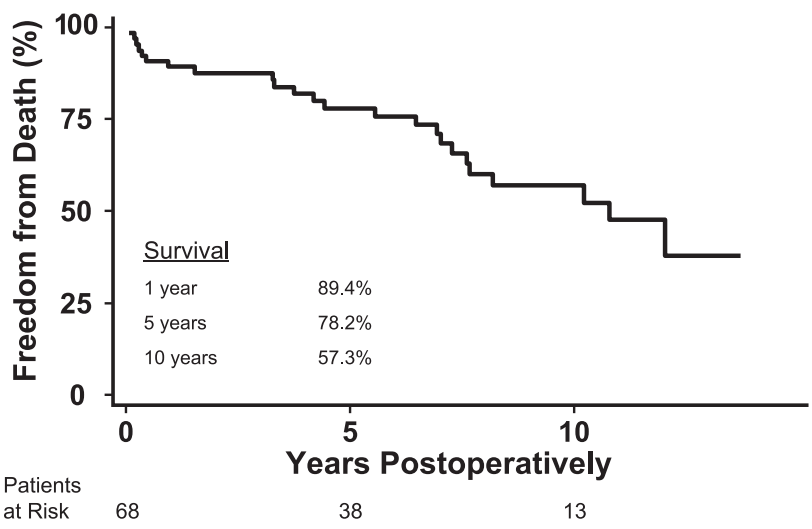

FIGURE 4. Long-term survival after surgery for extensive thoracic aortic dissection

large series and cumulatively was $16.5 \%$ for the 2 procedures. ${ }^{15}$ In our series it was $14.9 \%$. With increasing experience, the prevalence of major complications including tracheostomy has been substantially reduced (Figure 5). The only exception has been the need for prolonged ventilation.

The role of endovascular stent grafting of the dissected descending thoracic aorta in conjunction with conventional open aortic arch replacement of the ascending aorta and aortic arch (the so-called frozen elephant trunk procedure) has been proposed as an alternative to the 2-stage or 1-stage procedure. ${ }^{19}$ A rationale for this approach is to promote thrombosis of the false lumen and eliminate or substantially reduce the need for subsequent interventions on the downstream dissected aorta. Results from several large series of patients in whom this technique has been used have recently been reported. ${ }^{17,20-22}$ They have shown early mortality rates ranging from $1.4 \%$ to $13 \%$, stroke rates of $1 \%$ to $6 \%$, and most concerning, spinal cord ischemic injury rates of between $3 \%$ and $10 \%$. Renal failure requiring dialysis occurred in $1.4 \%$ to $20 \%$ of patients, and prolonged ventilatory support was required in $12 \%$ to $31 \%$ of patients. In the series reporting the lowest mortality and morbidity rates, patients with aneurysms measuring $5 \mathrm{~cm}$ or greater were excluded from the frozen elephant trunk procedure. ${ }^{17} \mathrm{~A}$ recent meta-analysis of 1103 patients undergoing a frozen elephant trunk procedure, approximately $82 \%$ of whom had aortic dissection, reported a pooled early mortality rate of $9.8 \%$ (95\% confidence interval [CI], 8.0-11.9), a stroke rate of $6.2 \%$ (95\% CI, 4.8-8.0), and a spinal cord ischemic injury rate of $7.9 \%(95 \% \mathrm{CI}, 6.3-9.9){ }^{23}$

The fate of the distal aorta and the need for subsequent aortic interventions are important considerations in the management of patients following procedures for extensive thoracic aortic dissection. With the 2-stage procedure, a second procedure to manage residual dissected aorta in the distal DTA and abdominal aortic segments is required 


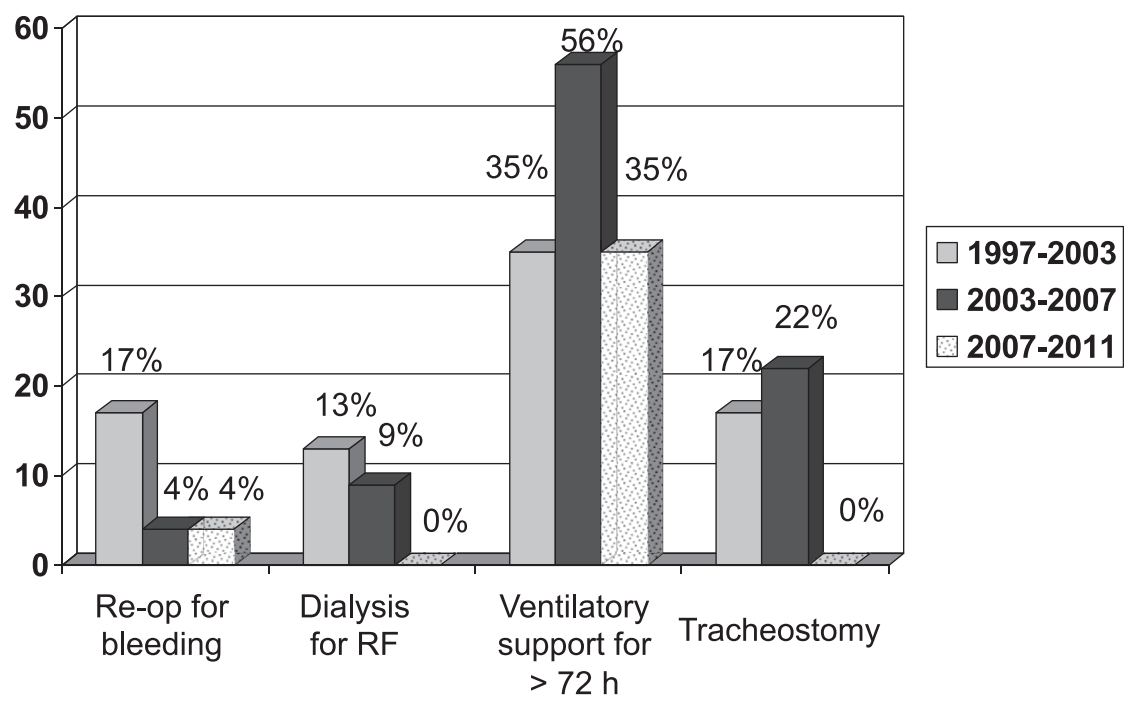

FIGURE 5. Prevalence of major complications according to date of operation. $R F$, Renal failure.

in virtually all patients. The long-term outcome of patients with aortic dissection after the second stage has not been separately analyzed in the large published series.

Follow-up of patients after the stented elephant trunk procedure for chronic aortic dissection is relatively short, and available for large numbers of patients in only a few reports. In the registry study of 8 European centers that implanted the E-vita graft (Jotec, Hechingen, Germany), cumulative freedom from secondary endovascular repair of the distal aorta at 4 years was $69 \%$, and freedom from the need for open surgical repair was $96 \% .^{21}$ However, the mean follow-up interval was $20 \pm 16$ months, and only 4 of the original 90 patients were followed for $>4$ years.

Our extensive follow-up of patents with the 1-stage procedure has demonstrated a low rate of reoperation on the contiguous downstream aorta $(6.7 \%$ at 10 years $)$ and an extremely low rate of growth of the distal aortic segment (Figure 2). These findings indicate that after replacement of the more proximal aneurysmal aortic segments and establishment of flow into both the true and false lumens, distal aneurysm formation is infrequent. Possible explanations for the low rates of growth and aneurysm formation include the stability of the aorta at the distal anastomosis that results from fixation by the aortic prosthetic graft and by a suture line that is buttressed with a strip of felt, as well as maintenance of flow into both the true and false lumens. With stent grafting, internal fixation is often incomplete at the distal end of the stent graft, and complete thrombosis of the false lumen surrounding the stent has not been uniformly observed. This lack of fixation allows for persistent pressurization of the false lumen around the stent graft and is a contributing factor to the high frequency of reinterventions. It remains 1 of the important limitations of this technique. Furthermore, it is likely that the true incidence of complete thrombosis is overestimated because of lack of delayed imaging which is not consistently employed with current radiologic techniques. The findings of our study also suggest that placement of uncovered stent grafts into the distal dissected aorta beyond a covered stent to promote remodeling and elimination of the false lumen in patients with chronic dissection may be unnecessary. ${ }^{24}$

\section{Limitations}

Our study is the largest to date to report outcomes associated with repair of chronic thoracic aortic dissection using a 1-stage open technique. However the results must be interpreted within the context of the study design. Observational in nature, the study involved the retrospective review of prospectively collected data in a referral-based tertiary care center. The procedures were performed on a single surgical service and the results may not be generalizable to other surgical centers. Surgical techniques evolved during the 17-year time period of the study. Although followup and imaging studies were not available for all patients, data from $77 \%$ of the entire cohort of hospital survivors was available for analysis of distal aortic growth rate.

\section{CONCLUSIONS}

Our extended experience has confirmed the feasibility and safety of 1-stage open repair of extensive chronic thoracic aortic dissection. The early mortality and morbidity rates do not exceed those reported for the first stage of the 2-stage procedure or for the stented ("frozen") elephant trunk procedure in large clinical studies. The prevalence of spinal cord ischemic injury is substantially less than that reported in several large clinical trials of hybrid procedures employing a stented elephant trunk. Substantial growth of the downstream aorta and the need for reoperation on this aortic segment have been infrequent during a followup interval that extends to 13 years. The 1-stage procedure 
represents a viable alternative to the 2-stage and hybrid procedures for extensive chronic aortic dissection confined to the chest, and it remains our procedure of choice.

\section{References}

1. Heinemann M, Laas J, Karck M, Borst HG. Thoracic aortic aneurysms after acute type A aortic dissection: necessity for follow-up. Ann Thorac Surg. 1990;49:580-4

2. Fattori R, Bacchi-Reggiani L, Bertaccini P, Napoli G, Fusco F, Longo M, et al. Evolution of aortic dissection after surgical repair. Am J Cardiol. 2000;86: 868-72.

3. Kazui T, Yamashita K, Washiyama N, Terada H, Bashar AH, Suzuki T, et al. Impact of an aggressive surgical approach on surgical outcome in type A aortic dissection. Ann Thorac Surg. 2002;74:S1844-63.

4. Geirsson A, Bavaria JE, Swarr D, Keane MG, Woo YJ, Szeto WY, et al. Fate of the residual distal and proximal aorta after acute type A dissection repair using a contemporary surgical reconstruction algorithm. Ann Thorac Surg. 2007;84:1955-64.

5. Gillinov AM, Lytle BW, Kaplon RJ, Casselman FP, Blackstone EH, Cosgrove DM. Dissection of the ascending aorta after previous cardiac surgery: differences in presentation and management. J Thorac Cardiovasc Surg. 1999; 117:252-60.

6. vonKodolitsch Y, Simic O, Schwartz A, Dresler C, Loose R, Staudt M, et al. Predictors of proximal aortic dissection at the time of aortic valve replacement. Circulation. 1999;100(Suppl):II287-94

7. Kouchoukos NT, Masetti P, Mauney MC, Murphy MC, Castner CF. One-stage repair of extensive chronic aortic dissection using the arch-first technique and bilateral anterior thoracotomy. Ann Thorac Surg. 2008;86:1502-9.

8. Kouchoukos NT. One-stage repair of extensive thoracic aortic aneurysm using the arch-first technique and bilateral anterior thoracotomy. J Op Techs Cardiovasc Surg. 2009;13:220-31.

9. Kulik A, Castner CF, Kouchoukos NT. Outcomes after total aortic arch replacement with right axillary artery cannulation and a presewnmultibranched graft. Ann Thorac Surg. 2011;92:889-97.

10. Hirose Y, Hamada S, Takamiya M, Imakita S, Naito H, Nishiyama T. Aortic aneurysms: growth rates measured with CT. Radiology. 1992;185:249-52.

11. Schepens MA, Dossche KM, Morshuis WJ, van den Barselaar PJ, Heijmen RH, Vermeulen FE. The elephant trunk technique: operative results in 100 consecutive patients. Eur J Cardiothorac Surg. 2002;21:276-81.
12. Safi HJ, Miller CC III, Estera AL, Huynh TT, Porat EE, Allen BS, et al Staged repair of extensive aortic aneurysms: long-term experience with the elephant trunk technique. Ann Surg. 2004;240:677-85.

13. Svensson LG, Kim KH, Blackstone EH, Alster JM, McCarthy PM, Greenberg RK, et al. Elephant trunk procedure: newer indications and uses. Ann Thorac Surg. 2004;78:109-16.

14. LeMairé SA, Carter SA, Coselli JS. The elephant trunk technique for staged repair of complex aneurysms of the entire thoracic aorta. Ann Thorac Surg. 2006;81:1561-9.

15. Etz CD, Plestis KA, Kari FA, Luehr M, Bodian CA, Spielvogel D, et al. Staged repair of thoracic and thoracoabdominal aortic aneurysms using the elephant trunk technique: a consecutive series of 215 first stage and 120 complete repairs. Eur J Cardiothorac Surg. 2008;34:605-15.

16. Kazui T. Invited commentary. Ann Thorac Surg. 2008;86:1509.

17. Sun LZ, Qi RD, Chang Q, Zhu JM, Liu YM, Yu CT, et al. Is total arch replacement combined with stented elephant trunk implantation justified for patients with chronic Stanford type a aortic dissection? J Thorac Cardiovasc Surg. 2009;138:892-6.

18. Roselli EE, Sepulveda E, Pujara AC, Idrees J, Nowicki E. Distal landing zone open fenestration facilitates endovascular elephant trunk completion and false lumen thrombosis. Ann Thorac Surg. 2011;92:2078-84.

19. Kato M, Ohnishi K, Kaneko M, Ueda T, Kishi D, Mizushima T, et al. New graftimplanting method for thoracic aortic aneurysm or dissection with a stented graft. Circulation. 1996;94(9 Suppl):II188-93.

20. DiEusanio M, Armaro A, DiMarco L, Pacini D, Savini C, Suarez SM, et al. Shortand midterm results after hybrid treatment of chronic aortic dissection with the frozen elephant trunk technique. Eur J Cardio Vasc Surg. 2011;40:875-80.

21. Pacini D, Tsagakis K, Jakob H, Mestres CA, Armaro A, Weiss G, et al. The frozen elephant trunk for the treatment of chronic dissection of the thoracic aorta: a multicenter experience. Ann Thorac Surg. 2011;92:1663-70.

22. Jakob H, Tsagakis K, Pacini D, DiBartolomeo R, Grabenwoger M, Mestres CA et al. The international E-vita open registry: data sets of 274 patients. J Cardiovasc Surg. 2011;52:717-23.

23. Cao P, DeRango P, Czerny M, Evangelista A, Fattori R, Nienaber C, et al Systematic review of clinical outcomes in hybrid procedures for aortic arch dissections and other arch diseases. J Thorac Cardiovasc Surg. 2012;144:1286-300.

24. Hofferberth SC, Newcomb AE, Yii MY, Yap KK, Boston RC, Nixon IK, et al. Combined proximal stent grafting plus distal bare metal stenting for managemen of aortic dissection: superior to standard endovascular repair? J Thorac Cardiovasc Surg. 2012;144:956-62. 